\title{
Modifications in the undergraduate MBBS pharmacology practical curriculum: The DMCH model
}

Previous issues of the IJP have focused on need for revision of undergraduate pharmacology practicals including animal experiments. ${ }^{[1-4]}$ Our department has been able to introduce some meaningful changes during the last 10 years with regard to pharmacology practicals as under:

\section{Practical Sessions}

These have been divided into four segments

1. Pharmacy practicals (including intravenous infusions)

2. Experimental pharmacology practicals

3. Prescription writing exercises

4. Therapeutic follow up cases

\section{Pharmacy practicals}

In view of ever-diminishing importance of practical pharmacy, these exercises have been replaced with demonstrations by teachers in small batches of 8-12 students each, who are not supposed to prepare these formulations. This is preceded by a discussion on the ingredients, their pharmacological effects, and therapeutic uses. Wherever possible, the commercial and household alternatives are explained, e.g., in flatulent dyspepsia, dimethicone instead of carminative mixture and in diarrhea, rice water instead of oral rehydration solution. Usually 2-3 student volunteers, by rotation, are involved in the process of preparation, while explaining the rationale of each step being executed along with to make it interesting. These exercises cannot be entirely dispensed with because of the Medical Council of India (MCI) and university regulations

New exercises

An intravenous (i.v.) infusion, in a simulated model, as a pharmacy exercise was introduced in 1995. Demonstrations of setting up of intravenous infusion are held; following which the students themselves have to set up these on inexpensive simulated models.

Model. Vein is simulated/represented by $15-20 \mathrm{~cm}$ piece of inexpensive, freely-available rubber tube [Figure 1] mounted on a wooden frog board [Figure 2]. The total set up is placed in a tray [Figure 3] to collect the outflow of the fluid being used. This simulated model can be used a number of times.

The students are instructed in the method of calculation of the dose and concentration to be used, actual dilution for preparation of infusion, setting up of IV infusion (including cannulation) and setting the drop rate, for infusion over a given period of time (e.g., 14 drops per minute for $1 \mathrm{~L}$ of fluid to be infused over 24 hours using a Murphy's drip chamber which is pre-calibrated to deliver $20 \mathrm{drops} / \mathrm{ml}$ ). The students are provided with butterfly cannula, i.v. infusion set, water-filled glass infusion bottle to set up the i.v. infusion. The dummy drug is usually ordinary tap water kept in a glass bottle 'labeled' as drug, out of which the students measure out the required volume. This dummy drug is added to the infusion bottle attached to the i.v. infusion set and scalp vein cannula set up by the student himself: The-students learn to handle syringes, needles, and i.v. infusion sets. Correct techniques of securing the cannula using a figure of eight are demonstrated [Figure 4]. The common practical difficulties faced in clinical situations are discussed. They are instructed regarding the labeling of the infusion bottles. Emphasis is laid on the drug used, effective concentration obtained, starting time of infusion and rate to be maintained. The students are taught to paste the label upside down, so that, it is easier to read the label while the infusion is going on.

\section{Experimental pharmacology practical}

The only practicals performed by the students are to study the effects of known and unknown drugs on rabbit eye. In these, they learn to differentiate between effects of drugs acting locally in the eye (miotics, mydriatics, and local anesthetics). They observe changes in pupillary size, light reflex, corneal reflex, and state of conjunctival blood vessels. The topical therapeutic uses of miotics, mydriatics and local anesthetics in clinical settings are stressed upon. Rationality of these drugs, therapeutic uses, adverse reactions, and contraindications are emphasized.

Experiments on coronary circulation, rabbit gut, frog blood vessels, which require sacrificing the animal, have been dispensed with.

In addition, experiments showing anticonvulsant effects, psychomotor impairment, anti-anxiety effect, anti-nociceptive effects etc are demonstrated to the students.

All these practicals are scheduled soon after the related topic has been discussed in the theory classes. This allows good correlation and reinforces the theoretical aspect in clinical settings.

\section{Prescription writing}

These exercises are scheduled at the end of the course to ensure good student understanding and participation. These are interactive sessions as students themselves spell out the options to be used. The teacher just co-ordinates to give a proper sequence or explains the use of a particular drug or relevant investigations in a given diagnosis. Each prescription is preceded by discussion on the management of related disease condition. Common emergency and non-emergency conditions are covered in these prescriptions. The prescriptions are followed by discussion of any alternate therapy as applicable in a particular clinical situation. All prescriptions 


\section{Figure 1: Rubber tube}

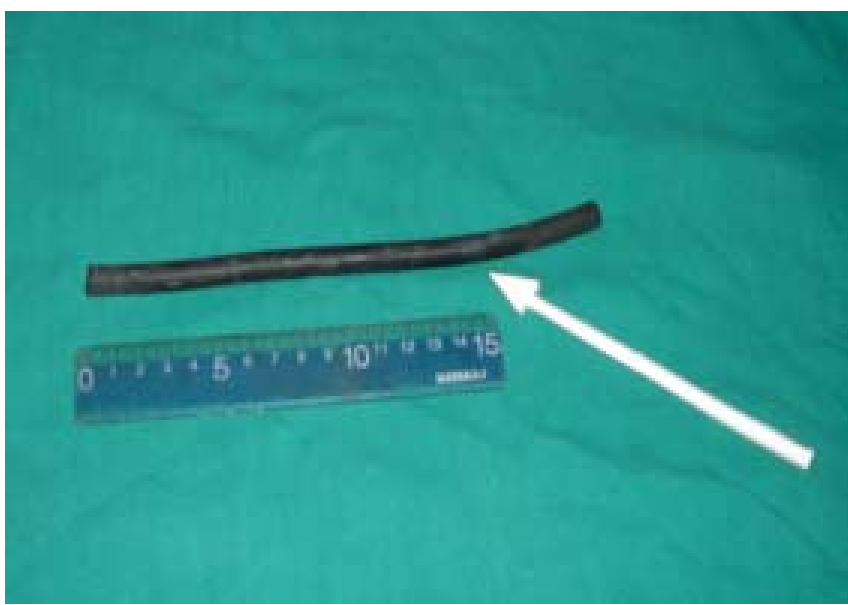

Figure 2: Mounting of rubber tube on frog board
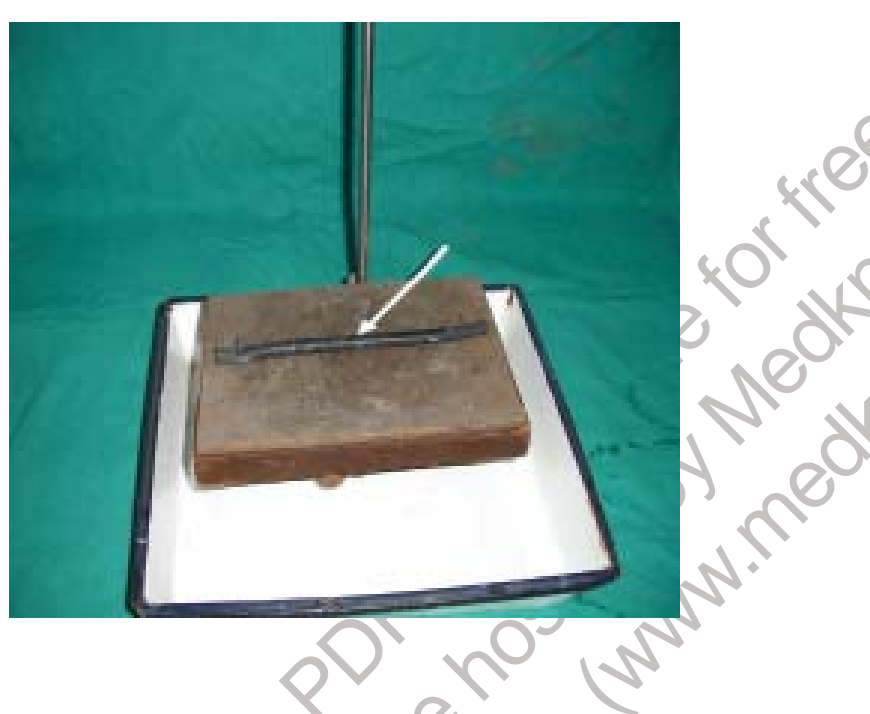

are reviewed on an annual basis in consultation with the teachers dealing with such conditions. This ensures that the students are abreast with current treatment strategies and have clinical orientation to the practical aspects after passing the $2^{\text {nd }}$ professional MBBS examination. This helps them in extrapolation of the knowledge of pharmacology to the applied aspect of the same.

\section{Therapeutic follow-up cases}

One follow up exercise of a clinical case is allotted to each student. A faculty member is deputed to make sure that only those cases are allotted who are expected to remain admitted for a week's time from the time of intimation, and are suffering from an illness having practical implications in drug therapy and are in 'must know' area. Allotment of cases by a faculty member ensures that the students do not 'cook up' cases. They are required to follow-up the case for one week and submit their report in a standard format mentioning brief patient identification and demographic data; chief complaints; relevant past, present and family history (including drug history); brief physical and relevant
Figure 3: Set up placed in the tray

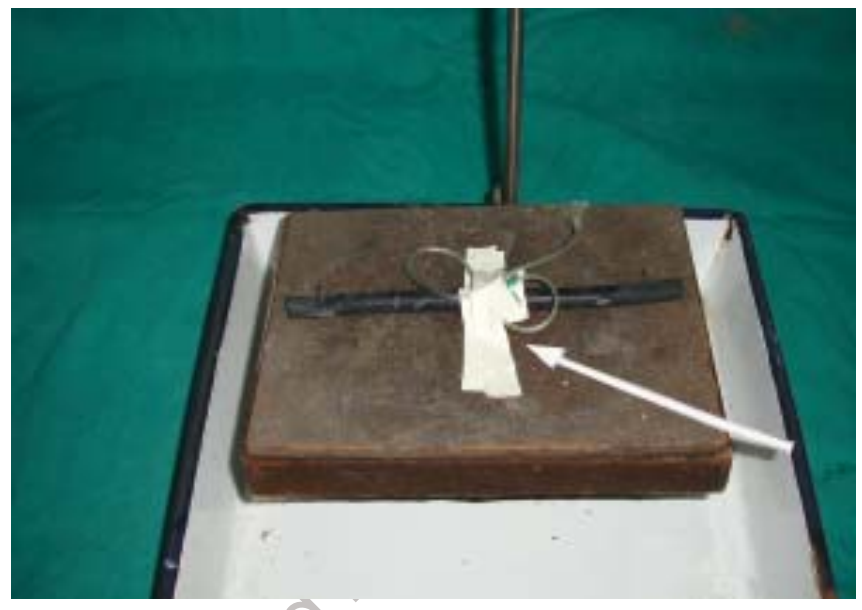

Figure 4: Starting iv drip using scalp vein cannula

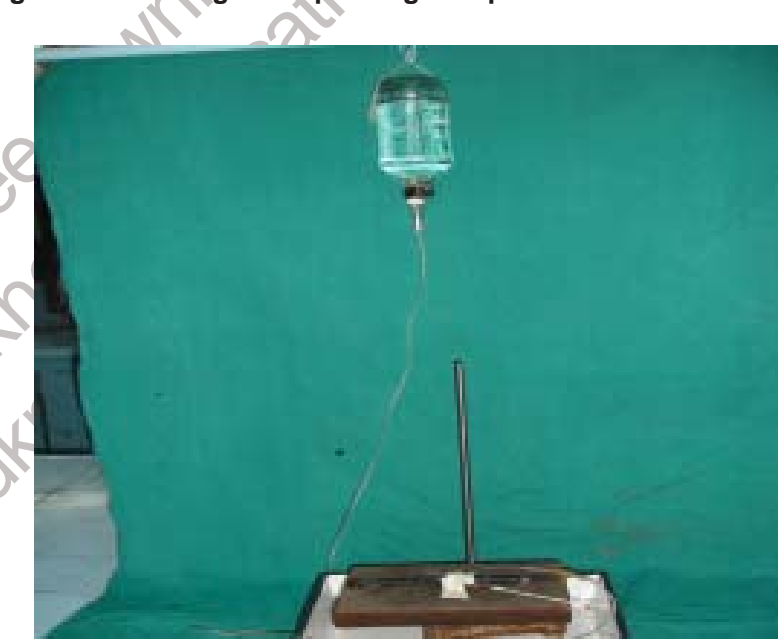

systemic examination; investigations over a period of one week; progress; treatment provided; outcome; final diagnosis; reasons for the particular line of treatment and a brief note on each drug (including cost analysis) used in the treatment of that particular patient. The students are required to explain in detail the use of each drug based upon the pathophysiology, clinical features, and interpretation of laboratory data. The stress is on pharmacotherapy, rational use of drugs, adverse drug reactions, drug interactions, and important precautions to be followed with a specific agent, selection of drug for the prevalent disease with special conditions, coexisting morbidity, if any. The exercise is reviewed and discussed by a teacher before or during the send-up examination. It forms the basis for starting the viva voce examination, if the examiner so desires.

\section{Discussion}

These modifications give a clinical orientation to the MBBS students, which have a bearing on their further training in final professional and internship. The students are given 
demonstrations regarding the correct use of the special dosage forms along with the relevant theory topics, for example, use of metered dose inhaler along with spacer, spinhaler, diskhaler and nebulizer (bronchial asthma); dispersion of a plain tablet and sustained release preparation (general pharmacology), advantage of rapid dispersion of dispersible tablet vs. plain and sustained release tablet in a glass of water (NSAIDs) and various types and preparations of insulin including pen injectors (anti-diabetic agents).

The dog BP exercise, though an excellent teaching and learning experience, is not possible because of CPCSEA guidelines. This could be substituted well with ComputerAssisted Learning (CAL) programme. In view of resource constraints (no multimedia projector available in the past), we have not been able to demonstrate various experiments using CAL software despite its availability (courtesy Prof. Raveenderan and IJP). Now with the availability of a laptop and LCD projector, have introduced the same in the form of demonstrations to our students, in small batches of $18-20$ students each.

We have been able to adopt and implement these innovative features in the curriculum with good degree of success. This has been reflected in the student feedback, which is an annual assessment of the teachers and teaching department. These modifications, coupled with few others, have brought our department from ninth position (year 2000 evaluation by MBBS admission batch 1995, 1996, and 1997) out of 16 teaching departments to first position (year 2004 evaluation)
These changes were introduced gradually over several years in a phased manner. Therefore, it was not possible to conduct a controlled parallel study and get a proper feedback from the students. However, there is a centralized student feedback of each department and each teacher in which feedback about departments/teachers is obtained after the students have passed the relevant university examination. We readily concede the point that this improvement is only an indirect result of several improvements in several other areas and does not reflect solely on the improvement in practical scheme.

\section{Acknowledgement}

The authors acknowledge Dr. Daljit Singh, Principal, Dayanand Medical College and Hospital for starting this student feedback programme. We are also thankful to the students for their truthfulness and sincerity in their comments.

S. Kaushal, S.C. Chopra, S. Arora Department of Pharmacology, Dayanand Medical College and Hospital, Ludhiana, Punjab, India. E-mail: skaushal1@yahoo.co.in

\section{References}

- Gitanjali B. Animal experimentation in teaching: Time to sing a swan song. Indian J Pharmacol 2001;33:71.

2. Gitanjali B. New wine in new bottle. Indian J Pharmacol 2004;36:63-4.

3. Hariharan TS. Need for changes in the practical pharmacology curriculum of medical undergraduates. Indian J Pharmacol 2004;36:181.

4. Mathur VS. Towards a more meaningful teaching of pharmacology. Indian J Pharmacol 2004;36:259-61.

\title{
International Medical Educator Program CMCL-FAIMER Fellowships 2007
}

Applications are invited from medical teachers for the Fellowship program 2007 jointly offered by Foundation for Advancement of International Medical Education and Research, USA and Christian Medical College, Ludhiana. The Fellowship is a year long program with 2 contact sessions of one week each and an educational project at fellow's home institution. Limited funds available for travel, stay and course fee.

Further details available at - http://cmcl.faimer.googlepages.com/home

For further information, please contact:

\author{
Dr. Tejinder Singh \\ Professor of Pediatrics and Director, \\ CMCL-FAIMER Regional Institute, Christian Medical College, \\ Ludhiana-141008. India \\ E-mail: cmcl.faimer@gmail.com
}

